\title{
Chaperones for intimate examinations: cross sectional survey of attitudes and practices of general practitioners
}

Joe Rosenthal, Janice Rymer, Roger Jones, Sarah Haldane, Shoshana Cohen, Jenny Bartholomew

Department of Primary Care and Population

Sciences, Royal Free and University College Medical School, University College London, London NW3 2PF Joe Rosenthal senior lecturer in general practice Shoshana Cohen senior academic registrar in general practice

Department of General Practice and Primary Care, Guy's, King's, and St Thomas' School of Medicine, King's College, London SE11 6SP

Roger Jones Wolfson professor of general practice

Sarah Haldane senior academic registrar in general practice

Jenny Bartholomew researcher

Department of Obstetrics and Gynaecology, Guy's, King's and St Thomas' School of Medicine

Janice Rymer senior lecturer in obstetrics and gynaecology

Correspondence to: J Rosenthal j.rosenthal@pcps. ucl.ac.uk
The conduct of intimate examinations in medical settings has been a subject of controversy for many years, because of potential difficulties and pitfalls for both doctors and patients. The royal colleges, ${ }^{1}$ the General Medical Council, and the defence organisations now emphasise the importance of ensuring that these examinations are not done by unaccompanied doctors. Some studies have shown, however, that the attitudes and behaviour of medical professionals are often at odds with these recommendations ${ }^{23}$ and that patients may not always welcome the offer, let alone the presence, of a third person in the consultation. ${ }^{4} \mathrm{We}$ describe the attitudes and practices of general practitioners regarding the involvement of chaperones during intimate examinations and identify barriers and concerns affecting their use.

\section{Participants, methods, and results}

A self completion questionnaire, with 38 items, was developed from themes emerging from patient focus groups and was piloted and modified before being sent to 1813 doctors from 18 primary care trusts in England, selected to achieve geographical and demographic diversity. A single postal reminder was sent to non-responders.

We analysed 1246 (69\%) of the questionnaires. The mean age of respondents was 45 (range 27-69); 754 $(61 \%)$ were male and $972(78 \%)$ were white. In all, 890 practices $(71 \%)$ were urban, with $132(11 \%)$ rural and $203(16 \%)$ intermediate. There were more female general practitioners (GPs) in rural practices and more GPs from ethnic minorities in urban practices.

A total of $457(37 \%)$ respondents had a policy on the use of chaperones. Altogether $517(68 \%)$ male GPs and $24(5 \%)$ women usually or always offered a chaperone; $410(54 \%)$ men and $9(2 \%)$ women usually or always used a chaperone; 60 males $(8 \%)$ and 344 females $(70 \%)$ never used one $\left(\chi^{2}=583.9,3\right.$ degrees of freedom, $\mathrm{P}<0.001)$.

Use of chaperones was correlated with increasing age (Pearson's $\mathrm{r}=0.18, \mathrm{P}<0.01$ ), belonging to $\mathrm{a}$ non-white ethnic group $\left(\chi^{2}=68.9, \mathrm{P}<0.001\right)$, and working in a smaller practice (Spearman's $\mathrm{r}=0.14, \mathrm{P}<0.01$ ).

Practice nurses were the most common chaperones with $969(78 \%)$ GPs reporting that they were likely or very likely to be used. A family member or accompanying person $(585 ; 47 \%)$, a non-clinical member of the practice staff $(535 ; 43 \%)$, a student or GP registrar $(275 ; 22 \%)$ or another doctor $(119 ; 10 \%)$ were alternatives. Most respondents rarely or never recorded the offer $(818 ; 66 \%)$ or the identity $(884$; $71 \%$ ) of a chaperone. A number of factors influenced the use of chaperones (figure).

\section{Comment}

The use of chaperones by male doctors has substantially increased since the 1980s and '90s and a
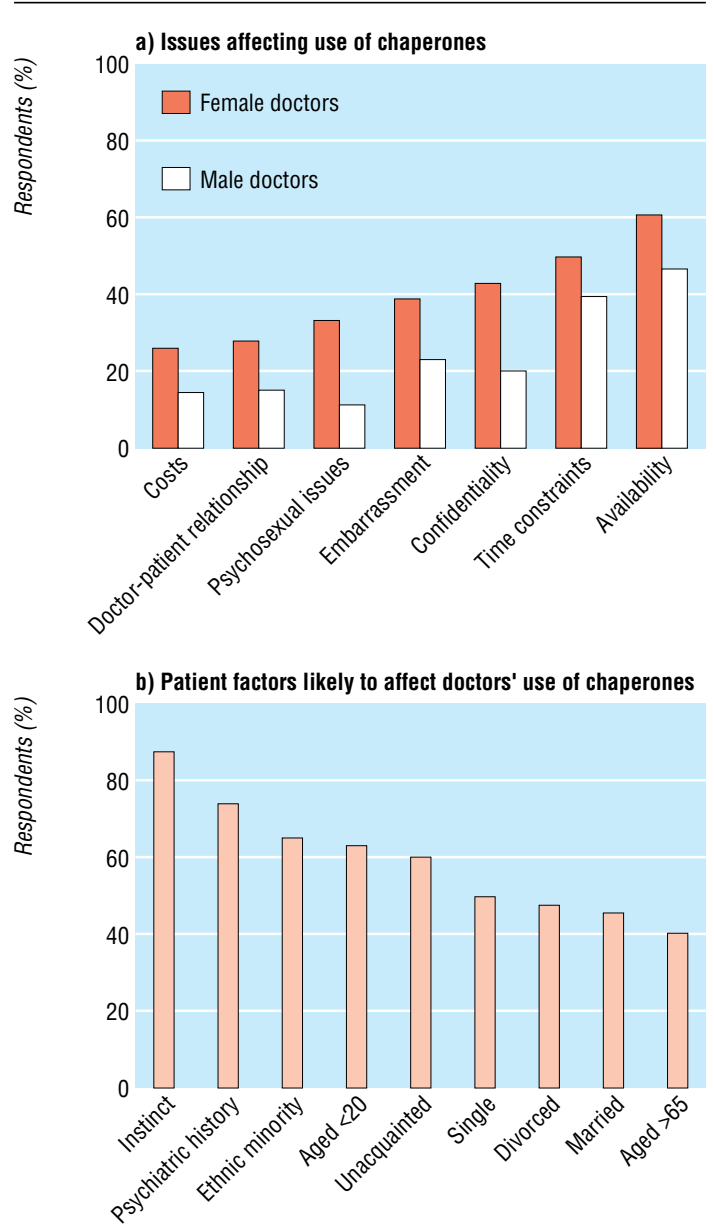

Issues affecting the use of chaperones and patient factors likely to affect doctors' use of chaperones

continuing low level of use by female doctors despite one third of practices having a policy. Record keeping about the offer and use of chaperones is poor, and significant barriers to the use of appropriate chaperones in general practice still undoubtedly exist. The recommendations of the royal colleges and other bodies are, therefore, difficult to implement fully. Their advice may be appropriate in most secondary care settings, but such recommendations may be difficult to translate into primary care practice. We suggest that more flexible guidance is needed for general practice, which must recognise the realities of current staffing and space arrangements, and take greater account of the wider context of the relationship between patients, their doctors, and the practice. ${ }^{5}$ Further research is needed into patients' views and wishes. We also need to

This article was posted on bmj.com on 3 December 2004: http://bmj.com/cgi/doi/10.1136/bmj.38315.646053.F7 


\section{What is already known on this topic}

Attitudes and behaviour of medical professionals are often at odds with the recommendations of the royal colleges and other bodies regarding the universal use of chaperones for intimate examinations

\section{What this study adds}

Use of chaperones by male doctors since the 1980 s and ' 90 s has substantially increased, but use by female doctors remains low

More flexible guidance is needed for general practice as well as further research into patients' views and wishes on the use of chaperones

gain more understanding of the circumstances in which problems might arise in this delicate area.
Contributors: RJ, JRo, and JRy had the original idea for the study. Data were collected by SH and SC. JB analysed the data and drafted a report. All authors wrote the paper. $\mathrm{RJ}$ is guarantor.

Funding: SH and SC were funded by the London Deanery GP Department as academic senior registrars in general practice. Competing interests: None declared.

Ethical approval: South East Multicentre Research Ethics Committee.

1 The Royal College of Obstetricians and Gynaecologists. Gynaecological examinations, guidelines for specialist practice. London: RCOG, 2002.

2 Jones RH. The use of chaperones by general practitioners. J $R$ Coll Gen Pract 1983;33:25-7.

3 Speelman A, Savage J, Verburgh M. Use of chaperones by general practitioners. BMJ 1993;307:986-7.

4 Stern V. Gynaecological examination post-Ledward: a private matter. Lancet 2001;358:1896-8.

5 Whitford DL, Karim M, Thompson G. Attitudes of patients towards the use of chaperones in primary care. Br J Gen Pract 2001;51:381-3.

(Accepted 10 February 2004)

doi 10.1136/bmj.38315.646053.F7

\section{Use and offering of chaperones by general practitioners: postal questionnaire survey in Norfolk}

Shaun Conway, Ian Harvey

Ten years ago in Norfolk, $65 \%$ of male general practitioners and $95 \%$ of female general practitioners never or rarely used a chaperone. ${ }^{1}$ The figures for offering chaperones were almost identical. The General Medical Council advises offering a chaperone for intimate examinations (those involving the genitals, anus, or breasts). ${ }^{2}$ The Royal College of Obstetricians and Gynaecologists advises using a chaperone for every intimate examination. ${ }^{3}$

A study of patients' preferences in Tyneside in 2001 found that $90 \%$ of women and $78 \%$ of men thought that a chaperone should be offered for intimate examinations. ${ }^{4}$ Half $(51 \%)$ of women wanted a chaperone to be used if their own male doctor was examining them. We wanted to see if the use of chaperones has changed in the past 10 years and as a result of the 2001 survey.

\section{Participants, methods, and results}

We invited a random sample of 200 (out of 348) male general practitioners in Norfolk and every female general practitioner (124) to complete a postal questionnaire. We used Epilnfo for data entry and SPSS for analysis.

Overall, 284 (87\%) responded. Mean age was 46.3 (men) and 43.8 (women). Only 23 were not white. The mean number of partners per practice was six. More than half $(155 ; 55 \%)$ were in dispensing practices. Three fifths of doctors $(170 ; 60 \%)$ described their practices as either rural or market town, 60 (21\%) as city, and $54(19 \%)$ as mixed or other.

The usual chaperone was the practice nurse for $75 \%(155 / 208)$ of those GPs who use a chaperone, but $18 \%(37 / 208)$ of doctors used a receptionist. Three fifths $(141 / 235 ; 60 \%)$ stationed the chaperone beside the patient and $36 \%(84 / 235)$ had the chaperone in the examination room but outside the curtain. Three fifths of doctors $(115 / 197 ; 58 \%)$ said that if they

This article was posted on bmj.com on 16 December 2004: http://bmj.com/cgi/doi/10.1136/bmj.38320.472986.8F

Use of chaperones by general practitioners. Values are numbers (percentages) of doctors

\begin{tabular}{|c|c|c|c|c|c|}
\hline & & Never & Rarely & Sometimes & Always \\
\hline \multicolumn{6}{|c|}{ Examining female patients } \\
\hline \multirow[t]{2}{*}{ Male doctors } & Uses a chaperone $(n=178)$ & $10(6)$ & $70(39)$ & $51(29)$ & $47(26)$ \\
\hline & Offers a chaperone $(n=176)$ & $7(4)$ & $33(19)$ & $58(33)$ & $78(44)$ \\
\hline \multirow[t]{2}{*}{ Female doctors } & Uses a chaperone $(n=106)$ & $72(68)$ & $25(24)$ & $9(9)$ & 0 \\
\hline & Offers a chaperone $(n=102)$ & $48(47)$ & $27(27)$ & $19(19)$ & $8(8)$ \\
\hline \multicolumn{6}{|c|}{ Examining male patients } \\
\hline \multirow[t]{2}{*}{ Male doctors } & Uses a chaperone $(n=178)$ & $141(79)$ & $31(17)$ & $6(3)$ & 0 \\
\hline & Offers a chaperone $(n=167)$ & $122(73)$ & $37(23)$ & $6(4)$ & $2(1)$ \\
\hline \multirow[t]{2}{*}{ Female doctors } & Uses a chaperone $(n=106)$ & $53(50)$ & $40(37)$ & $11(10)$ & $3(3)$ \\
\hline & Offers a chaperone $(n=104)$ & $39(38)$ & 32 (31) & $17(16)$ & $16(15)$ \\
\hline
\end{tabular}

The Surgery, Hingham, Norfolk NR9 4JG

Shaun Conway general practitioner Population Health Group, School of Medicine Health Policy and Practice, University of East Anglia, Norwich NR4 7TJ

Ian Harvey professor of epidemiology and public health

Correspondence to: S Conway Shaun.Conway@ nhs.net 